\title{
ENTRE LA CIENCIA Y LA CULTURA: LA CONFORMACIÓN DE DISCURSOS MÉDICOS SOBRE LA HOMOSEXUALIDAD EN EL CONTEXTO DEL SURGIMIENTO DEL VIH/SIDA EN COSTA RICA
}

\author{
BETWEEN SCIENCE AND CULTURE: THE MEDICAL DISCOURSIVE \\ CONFIGURATION OF HOMOSEXUALITY DURING THE EMERGENCE \\ OF THE HIV/AIDS IN COSTA RICA
}

José Daniel Jiménez Bolaños Mario Bahena Uriostegui

Recibido: 05/03/2017 Aceptado: 28/05/2017

\section{Resumen}

En este artículo se analiza la manera en que el discurso médico conceptualizó y representó a la homosexualidad cuando surge el VIH/sida en Costa Rica. Se hace una reflexión teórica en torno al tema de la sexualidad como objeto de estudio, y se problematizan las diferentes maneras con las cuales se construye la subjetividad, seguidamente se analizan los discursos periodísticos. La dinámica saber/poder sexual se articula y se institucionaliza en el discurso médico a través de los medios de comunicación, ambas instituciones, junto a la Iglesia, desempeñaron un papel fundamental en la propagación de imágenes abyectas sobre la homosexualidad masculina principalmente. El discurso médico no fue homogéneo, ya que hubo voces de resistencia frente a la postura hegemónica.

Palabras clave: Sexualidad; homosexualidad; discurso médico; discurso religioso; sida.

\begin{abstract}
This article seeks to analyze the ways in which medical discourse conceptualized and represented homosexuality in the years where HIV/AIDS emerged in Costa Rica. First, a theoretical reflection is made on the issue of sexuality as an object of study that constructs subjectivity at the same time. Then, an analysis of the journalistic discourses is made. The dynamics of power/knowledge in sexuality are articulated and institutionalized in the medical discourse through the media; in the case of Costa Rica both institutions, along with the Church, played a key role in the spread of abject images on male homosexuality. On the other hand, the medical discourse was not uniform; it is possible to find voices of resistance to the hegemonic position.
\end{abstract}

Keywords: Sexuality; homosexuality; medical discourse; religious discourse; AIDS. 
El locus de despliegue de la sexualidad tradicional

Desde hace unos meses me he dedicado a recortar artículos, reportajes, ensayos periodísticos, que abordan el tema del sida, y por ende, según la mecánica manera de pensar de la mayoría de los autores, de la homosexualidad. Con este material que estoy juntando, proyecto hacer un bestiario del sentimiento humano en donde-lamentablemente, lo que predomina es el odio, el prejuicio, la saña y como si esto no bastara, todo ello coronado por la muerte.

José Ricardo Chaves, Paisaje con Tumbas Pintadas en Rosa

Si bien los primeros casos de sida que se registran en Costa Rica se presentaron en pacientes hemofílicos, no es hasta los años de 1985 y 1986 cuando empiezan a documentarse casos de hombres que practican sexo con hombres homosexuales y bisexuales con sida (Ministerio de Salud 9). A partir de ese momento, se empezó a gestar toda una discusión nacional sobre dicha temática, la cual reveló los límites conceptuales del discurso médico sobre la compleja sexualidad dentro de la sociedad costarricense. Al tratar de ofrecer un entendimiento, así como poder controlar lo que se consideraba un contagio epidémico de transmisión sexual, el discurso médico casi por una década categorizó, vilificó y otorgó una identidad homogénea a quienes no practicaban o se identificaban con la sexualidad tradicional. Y, más importante, el discurso médico delimitó una línea imaginaria entre la sociedad costarricense heteronormativa y aquellos que no pertenecían a esta comunidad imaginada, una visión propagada por los medios masivos; este planteamiento se parecía más a un discurso religioso que a uno médico.

Antes de que la Organización Mundial de la Salud (OMS) eliminara a la homosexualidad de su corpus internacional de clasificación de enfermedades y problemas de salud en 1990, el discurso médico nacional costarricense se convirtió en un foco de despliegue de un entendimiento de la sexualidad tradicional que marginalizó las formas alternas de concebir lo sexual. En esta investigación se emplearon fuentes periodísticas, ya que primero muestran el grado de intensidad en la discusión iniciada a partir de las décadas de los ochenta y noventa sobre el tema; segundo porque fue una de las principales plataformas utilizadas por los médicos para exponer sus ideas a un público mayor, y tercero, el acceso a dichos discursos es bastante amplio en la sociedad costarricense.

Fue a través de los medios de comunicación masivos que se construyó y se dispersó un entendimiento de colectividad sobre aquellos que practicaban una sexualidad no tradicional: se hacían declaraciones sobre estos cuerpos cuando se adoptaban posturas estatales y médicas que por un lado trataba de analizarlos y al mismo tiempo que los marginalizaba; a veces, se describieron a estas colectividades en cierta forma 
que negaban su humanidad, y más importante, se tomaron decisiones retóricas sobre estas sin su concomimiento y sin derecho de réplica.

El discurso médico ${ }^{1}$ se convirtió en el único enlace entre una forma hegemónica y formas alternas de entender la sexualidad; este reducía a la sociedad entre un nosotros y un ellos, creando dos colectividades que solo podían ser antagónicas. La relación de poder entre las lógicas médicas, con acceso a medios masivos de comunicación sobre aquellos cuerpos alterizados por su discurso, era desigual pues los segundos no tenían el mismo acceso a las plataformas mediáticas para una réplica capaz de cuestionar la arenga por la cual fueron imaginados, reducidos y marginalizados.

Esta relación entre un discurso tradicional, emanado por la clase médica y propagado por los medios de comunicación sobre los cuerpos de la sociedad costarricense, reflejó la necesidad de las élites epistemológicas de categorizar lo fenomenológicamente diferente en un ámbito social que cada vez se hacía palpable, más que una descripción ontológica de una realidad que apenas se estaba formando. Por eso, el análisis de la relación entre la perspectiva cultural, el poder social de los medios de comunicación y el poder político del locus enunciador desde donde se desplegó el entendimiento de la sexualidad es imperativo para encontrar la génesis de ciertas tendencias tabúes.

Así, se entiende que los cuerpos entran en una identidad sexual/género definida por el mismo discurso desplegado desde las élites epistemológicas de una sociedad. Tradicionalmente, en la academia se ha entendido la identidad sexual como parte del construccionismo social; en otras palabras, la sexualidad es un objeto/sujeto construido en el seno de la cultura y el producto de un juego de lenguaje determinado, ubicable en un contexto específico y con una historia localizable (Vendrell 12). Si bien se puede analizar una dicotomía entre lo material y lo simbólico, no ha habido una explicación convincente que supere esta forma poskantiana de ver la realidad. Por eso, por "sujetos sexuales", se hace referencia al entendimiento social de vivir y experimentar la sexualidad sobre la cual orbita una estructura social y legal que, en su intento de resguardarla, la crea y perpetúa como un objeto. Este contexto sociocultural y legal sobre la sexualidad convierte al cuerpo sexualizado en un "sujeto" al desplegar una presupuesta identidad social con ciertas expectativas. Este concepto de la sexualidad objeto/sujeto a posteriori, es decir, una identidad sexual efectuada por la cultura que se materializa en el cuerpo sexualizado, se desarrolla en contraposición a la conceptualización esencialista de la sexualidad, a priori.

Esta última entiende la sexualidad desde antes de la formación de la sociedad o antes que el individuo se incorpore a esta, y la plantea como un ente esencial que propulsa la identidad de la persona dentro de un orden social natural en el cual el individuo está situado. El discurso de la concepción del género, la sexualidad a priori se presenta a sí misma como un reflejo de la realidad sin mediación de la cultura o la historia. La visión de la sexualidad anclada en la naturaleza y la biología es usualmente apoyada por los discursos y epistemologías hegemónicas, los sistemas 
de salud, las políticas sexuales, el pensamiento científico-positivista, las instituciones religiosas, la sexología y la psiquiatría (Weeks 17-18). Su fuerte viene de su naturalización, de una constante repetición de ciertas formas de entender la sexualidad por la cual se desarrollan patrones sociales aceptables: una performatividad.

Si se concibe a la sexualidad como una concreción corporal de los discursos hegemónicos resulta evidente que la construcción de este concepto es mucho más compleja que una dicotomía natural/cultural. En efecto, se puede estudiar cómo estos conceptos no solo son limitados y limitantes, sino que esconden el despliegue de la subjetividad sexual tradicional. Por ejemplo, las expectativas culturales nacen de una constante repetición corporal de una forma de "ser" que naturaliza las expectativas históricamente creadas; por lo cual se establece como una práctica socialmente aceptable. Al respecto, Judith Butler (2007) hace unas observaciones del papel de la cultura en el desarrollo de concebir la sexualidad como una realidad natural que precede su configuración cultural:

Si se refuta el carácter invariable del sexo quizás esta construcción denominada "sexo" está tan culturalmente constituida como el género; de hecho, quizá siempre fue género, con el resultado del que la distinción entre sexo y género no existe como tal... Como consecuencia, el género no es a la cultura lo que el sexo es a la naturaleza; el género también es el medio discursivo/ cultural a través del cual la 'naturaleza sexuada' o 'un sexo natural' se forma y establece como "prediscursivo", anterior a la cultura, una superficie politicamente neutral sobre la cual actúa la cultura... Esta producción del sexo como prediscursivo debe entenderse como el resultado del aparato de construcción cultural nombrado por el género (54-56).

El discurso tradicional entiende la sexualidad a priori sin tomar en cuenta el papel del discurso de la sociedad que lo ha naturalizado, se revela el desarrollo de la identidad de sexo/género dentro de la cultura. No obstante, como la sexualidad sigue más a las postulaciones a posteriori -la cultura-, entonces se encuentra en constante amenaza de revelar su construcción cultural para quienes consideran al sexo como algo natural. Al hablar de género, para Butler este "no es, de ninguna manera, una identidad estable; tampoco es el locus operativo de donde procederían los diferentes actos; más bien, es una identidad débilmente construida en el tiempo: una identidad instituida por una repetición estilizada de los actos" (296-297). Además, lo concibe como la repetición de la misma -la naturalización de las expectativas culturales- una única forma de entender la sexualidad que crea la subjetividad de género-sexualidad.

\section{La sexualidad como forma de vivir las identidades sociales}

La complejidad, que resulta de las tendencias sexuales y las identidades socioculturales que se desarrollan tanto en el centro como en las periferias de una cultura, hace difícil nombrar a grupos enteros sin caer en el mismo problema estudiado en este artículo: 
otorgar una identidad sexual preestablecida con un discurso de inclusión o exclusión social sin dejar que los cuerpos decidan sobre su propia sexualidad, ya sea dentro o fuera de las etiquetas existentes.

Ante esto, se debe tener cuidado de que el vocabulario empleado no presuponga una entidad ontológica para evitar la imposición de formulismos desde un lugar de poder de discurso. Al respecto Mario Pecheny (13) escribe sobre la problemática de denominar a los sujetos sobre los cuales se habla como:

Personas no heterosexuales, homosexuales, gays, lesbianas, travestis, transexuales, transgénero, trans, bisexuales e intersex, miembros de la diversidad sexual, personas y grupos que no se ajustan a los patrones heteronormativos o heterosexistas, miembros de las minorias sexuales, disidentes sexuales... y las letras y siglas como GLTTTBI.

Para soslayar que nuestro vocabulario se convierta en otra forma de perpetuar una forma de concebir la sexualidad limitada y limitante, se ha usado el término sexualidad heteronormativa o tradicional frente a frente la sexualidad no-heteronormativa o alterna para hacer referencia no tanto a la variedad sexual en sí, sino más bien a la dicotomía desplegada desde el discurso médico propagado por los medios de comunicación en Costa Rica.

En esta retórica mediática, el heterosexismo va de la mano con un determinismo biológico, las diferencias entre mujeres y hombres, entre actos reproductivos y no reproductivos, entre comportamientos "naturales" y "desviados". Esta dicotomía aceptó como natural lo socialmente aceptable y convirtió en un acto non grato aquello que no se conformó con la expectativa de la comunidad imaginada. Esto contribuyó a la conceptualización de la sexualidad como una esencia monolítica, como un aspecto biológico, donde la sociedad no tuvo ningún papel en su construcción y perpetuación. Al mismo tiempo, se fetichizó el lenguaje, pues se esperaba que las palabras (de alguna forma $u$ otra) describieran una realidad ontológica sin estar consciente del papel creador y otorgador de identidades a esa realidad. Judith Butler llama "discriminaciones discursivas" (70) el hecho de delimitar, crear y etiquetar grupos con nombres o asociaciones peyorativas.

Por eso, el análisis del discurso de los periódicos nacionales y los medios de comunicación es fundamental para comprender la construcción en el imaginario colectivo costarricense de dichas identidades sociales. En este caso, los periódicos se convierten en la plataforma de alcance nacional de reafirmación de los discursos hegemónicos sobre el entendimiento de la sexualidad, aun cuando reclamen que sus intereses son exclusivamente clínicos. Para Michel Foucault (2005), esta "producción del discurso está a la vez controlada, seleccionada y redistribuida por cierto número de procedimientos que tienen por función conjurar sus poderes y peligros, dominar el acontecimiento aleatorio y esquivar su pesada y temible materialidad" (14). 
El discurso no es solo la forma de traer al mundo simbólico una forma de entender la realidad, sino que se convierte en la manera de controlar, dominar y manipular esa realidad. Por eso, para Butler (2011) no

Se puede separar el poder del discurso para producir una realidad social, de una parte, del poder del discurso para describir una realidad existente, de la otra. Ambas cosas suceden al mismo tiempo el lenguaje como forma de negar la humanidad a aquellos que hacen ciertos actos (70-71).

Butler (2004) llama "rituales ceremoniales" a esta violencia discursiva que se reproduce por la cultura a través del tiempo:

En tanto que enunciados, funcionan en la medida en que se presentan bajo la forma de un ritual, es decir, repetidos en el tiempo, y por consiguiente, presentan un campo de acción que no se limita al momento del enunciado mismo. El acto de habla ilocucionario realiza su acción en el momento mismo en que se pronuncia el enunciado, y sin embargo, en la medida en que el momento está ritualizado, nunca es simplemente un momento único. El "momento" en un ritual es una historicidad condensada: se excede a si mismo hacia el pasado y hacia el futuro, es un efecto de invocaciones previas y futuras que al mismo tiempo constituyen y escapan a la enunciación (18-19).

Este "daño lingüístico, que interpela y constituye a un sujeto" (Butler 17) propagado por los periódicos, le permitió al discurso médico costarricense convertirse en un locus del despliegue de la sexualidad tradicional (Butler 7). En palabras de Michel Foucault (2005), el discurso médico fue uno de los muchos "focos emisores de los discursos" desde los cuales la concepción hegemónica de la sexualidad y del género bombardeaba al resto de la sociedad costarricense. Por esta razón, el discurso médico se encontraba al mismo nivel de otros locus emisores del discurso tradicional desde donde se dispersaba un entendimiento tradicional de la sexualidad: la Iglesia católica de Costa Rica, como se verá más adelante, tiene una gran influencia en las ópticas de muchos discursos médicos.

\section{Contextualización y representaciones sociales del VIH/sida}

Se argumenta que cuando se dio a conocer públicamente que la enfermedad estaba vinculada con la sexualidad, la sangre y las drogas, se presentaron reacciones de pánico e histeria en los diferentes sectores de la sociedad (Grmek 25). El primer anuncio oficial sobre su existencia se hizo el 5 de junio de 1981 cuando el Centro para el Control y la Prevención de Enfermedades en Atlanta, Georgia expuso cinco casos de neumonía, con la particularidad de que todos los enfermos eran hombres jóvenes y homosexuales (Grmek 27). A finales de ese año se contabilizaban alrededor de 159 casos registrados por los servicios sanitarios estadounidenses, 
y la enfermedad no tenía nombre científico; por esta razón en varios contextos empezó a ser llamada como la "neumonía gay", el "cáncer gay" o "la peste gay"; incluso, se llegó a emplear el acrónimo GRID (Deficiencia Inmunológica Gay, por sus siglas en inglés). Para 1982, la enfermedad fue bautizada con su nombre actual, al obtener las pruebas irrefutables de que su causa es viral (Grmek 35-38).

Una revisión de la historia de las representaciones sociales del sida muestra que durante la década de los ochenta la enfermedad empezó a ser asociada con la ya marginada población homosexual en casi todas las regiones afectadas. Los modos de infección relacionados con la moralidad fueron asimilados y difundidos por los medios de comunicación occidentales, erigiéndose como las representaciones sociales prevalecientes de las personas infectadas por el virus (Labra 244).

La década de 1990 marcó un cambio en las representaciones generalizadas de grupos de alto riesgo. Cuando el virus del VIH/sida fue identificado, los usuarios de drogas intravenosas y los hombres homosexuales fueron vistos como los principales culpables. Sin embargo, durante esa década otros grupos, como las prostitutas, los bisexuales y heterosexuales, también fueron diagnosticados con altos grados de infección (Labra 245).

Durante la década del 2000, un nuevo arquetipo de las personas infectadas empezó a imponerse: el quienes viven con el VIH/sida. Esta representación refleja, sin duda, una visión más humana de las circunstancias de vida de las personas con VIH y sugiere un enfoque empático hacia el sufrimiento de aquellos cuya infección conlleva el estigma de la exclusión social. La imagen ya no es una de portadores, víctimas o sobrevivientes, sino el mensaje público de que es posible vivir como una persona con VIH.

Esta nueva perspectiva se construyó gracias a los avances médicos puestos en marcha desde la década de 1990, los cuales han transformado el panorama de la atención de salud. Anteriormente, un diagnóstico de VIH-positivo era considerado como una sentencia de muerte. Ahora es más probable que sea visto como una enfermedad crónica (Labra 245).

No existen estudios sistemáticos que aborden el tema de la recepción y las representaciones sociales formadas a partir del surgimiento del VIH/sida para toda la región latinoamericana; sin embargo, se pueden hacer algunos apuntes relacionados con las consecuencias de la aparición de dicha enfermedad en la conformación de grupos civiles organizados por la diversidad sexual.

Por ejemplo, en Argentina, durante la dictadura militar (1967) se formó el grupo gay Nuestro Mundo y en la década de los ochenta resurgieron varios movimientos de la comunidad de lesbianas, gais, bisexuales y transexuales (LGBT); como es el caso del Grupo Homosexual Argentina, el cual tenían como principal objetivo luchar contra las persecuciones que llevaba a cabo el Estado contra los lugares de socialización gay. En Uruguay a partir de 1985 se crearon el Movimiento de Liberación Homosexual, Mujer y Mujer y Homosexuales Unidos, lo que dio cabida a celebrar el día de orgullo gay por 
primera vez en 1992 en dicho país. Por su parte, en Chile ocurrió una gran represión debido a la dictadura militar, la cual fue exacerbada con la aparición de la enfermedad en los ochenta (Gómez 79-92).

En el año de 1995 en Ecuador, a pesar de la gran inestabilidad económica y política y de la discriminación, el movimiento gay se organizó, y dos años después logró despenalizar la homosexualidad, como lo había hecho Colombia en 1981. Para 1998, Ecuador se convirtió en el tercer país del mundo en prohibir la discriminación por orientación sexual a nivel constitucional. Mientras tanto, en Perú surgió el Movimiento Homosexual de Lima en 1982, y durante la segunda mitad de la década de los ochenta se enfrentaron a la pandemia, lo cual causó la muerte de gran parte del liderazgo LBGT peruano. En Bolivia también durante la década de 1980 y 1990 se crearon más de 10 organizaciones LGBT. En 1995, en Venezuela surgió el Movimiento Ambiente de Venezuela, con objetivos variados, por ejemplo, el abordaje de la problemática del $\mathrm{VIH} /$ sida. Lo anterior evidencia la fuerza que tuvo el VIH/sida para la movilización (Gómez 104-120).

En Centroamérica, El Salvador dio paso a las primeras organizaciones en la zona con el objetivo de prestar ayuda asistencial a las personas afectadas por VIH y el sida; pero los escuadrones de la muerte y otros grupos las han asaltado para silenciarlas, lo cual evidencia un alto grado de violencia. Por su parte, Guatemala, además de sufrir las consecuencias de una guerra civil que significó muchas muertes, también es uno de los países más pobres y violentos del área; la represión desatada contra los homosexuales cuando surgió el VIH/sida fue bastante amplia (Gómez 128-159). En Costa Rica, para 1987 se habían creado tres organizaciones, la Asociación de Lucha Contra el SIDA, el grupo lésbico Las Entendidas y la Comunidad Ecuménica de la Fe, entre sus principales objetivos estaba frenar el grado de contagio entre homosexuales y prestar ayuda asistencial a los enfermos (Jiménez 80).

La forma de conceptualizar y representar la enfermedad en gran parte de Occidente tuvo una gran influencia en el contexto costarricense. Las representaciones sociales durante las décadas de los ochenta y noventa enfatizan la abyección de ciertos grupos, entre estos los homosexuales, y como se evidencia en el contexto latinoamericano, el discurso y la práctica de medidas represivas tuvieron como consecuencia la conformación de grupos organizados por la diversidad sexual.

\section{“Una grave descomposición social": El discurso médico en disputa}

En 1993, la editorial de la Universidad de Costa Rica publicó el libro Salud y Seguridad Social, escrito por Juan Jaramillo Antillón, quien, bajo la presidencia de Luis Alberto Monge Álvarez, fue ministro de Salud (1982 y 1986). En dicha obra, hace un repaso de los principales desafíos del sistema de salud nacional. En sus primeras páginas afirma que: 
Mientras mejoramos los indices de salud al disminuir la mortalidad y aumentar los años de vida, no solo nos estamos llenando de las enfermedades del anciano, de difícil tratamiento, sino de algo peor, como es la aparición, cada día mayor, de una patología social muy difícil de combatir, representada por el alcoholismo y la drogadicción en nuestra juventud, los delitos sexuales, el embarazo en las adolescentes, el aumento de las madres solteras, los conflictos en los hogares, la agresión psíquica o física de los niños, el homosexualismo y para acabar de agravar la situación, los trastornos ecológicos en nuestro "medioambiente" (10).

Su discurso conceptualiza a la homosexualidad como uno de los síntomas de una supuesta patología social que amenaza con propagarse a la sociedad costarricense. El concebir la homosexualidad como un problema de salud pública encuentra muchas similitudes con la discusión médica llevada a cabo durante la segunda mitad de la década de los ochenta dentro del contexto de aparición del VIH/sida. En esa época, ministros, miembros de comisiones médicas y médicos, en general, abordaron el tema de la sexualidad no heteronormativa bajo un lente de patologización. Los médicos profesionales no fueron un grupo homogéneo y -en relación con sus reacciones frente a la epidemia del sida- muchos de los prejuicios encontraran eco en el sentir popular; no obstante, estos voceros se encontraban en un papel de poder discursivo cuyos pronunciamientos tenían un peso oficial. Por eso, se vuelve necesario un análisis detallado de la forma en que dicho gremio imaginó, a partir de su discurso, a quienes no formaban parte de la sexualidad tradicional (Robinson y Wilson 702).

Cuando empezaron a surgir más casos de portadores en el país a mediados de los ochenta, se evidenció que la población presentaba un gran desconocimiento sobre los aspectos más fundamentales del virus y la enfermedad. Para 1985 todavía se plantearon interrogantes acerca del grado de mortalidad del sida, si era necesario evitar lugares públicos y concurridos, se planteaba de forma explícita la necesidad de que "los investigadores hablen más claramente sobre los cuidados que han de tomarse" (Bogantes 14). Durante este período temprano circularon muchos mitos, por ejemplo, la posibilidad de contagiarse por medio de la saliva o por la picadura de un mosquito (Monge 12).

Las declaraciones no se hicieron esperar; en agosto de 1985, en una conferencia de prensa de médicos en el Hospital México, se informó sobre los principales grupos de riesgo: homosexuales, drogadictos y hemofílicos (La Nación 2). Para ese año, todavía no había registros de ningún hombre gay, que tuviera sexo con otros hombres, o presentara signos de la enfermedad en Costa Rica; sin embargo, ese hecho no impidió que, desde un inicio, el sida se vinculara directamente con la sexualidad no heteronormativa. En septiembre se publicó una extensa lista de medidas de prevención, dividida por grupos de riesgo, así como los posibles síntomas que podría presentar una persona portadora (La Nación 12). 
A partir de esto, el discurso médico con proyección mediática empezó a configurarse. En un artículo de 1985, Edgar Mohs, quien un año después sería ministro de Salud, abordó el tema del VIH/sida, en donde calificó a la irresponsabilidad individual como la causante de catástrofes en la sociedad. El médico apuntó que "haber roto en mil pedazos las normas tradicionales de comportamiento sexual es otro ejemplo de que no se puede jugar irresponsablemente e impunemente con la naturaleza" (15).

Estas primeras declaraciones pusieron las bases de la perspectiva médica sobre las cuales se basaron futuras afirmaciones; por ejemplo, la idea de que la aparición del sida tenía una relación directa con el comportamiento sexual de las personas. Además, se empezó a conceptualizar la enfermedad como el resultado de un quiebre en el "orden natural". En lugar de tratar a la enfermedad en términos puramente científicos, una parte del discurso médico transformó al sida en una metáfora de los males de la sociedad. Entre las primeras acciones que tomó el Ministerio de Salud para enfrentar la epidemia fue crear la Comisión Nacional de SIDA (La Nación 1). Así como la prohibición de aceptar donadores de sangre pertenecientes a los grupos de riesgo o con tuvieran síntomas sospechosos (La Nación 2), y la invitación de expertos extranjeros para que impartieran cursos sobre la enfermedad en el país ( $\mathrm{La}$ Nación 9). A esta reacción de pánico le acompañó un discurso que ponía a la comunidad que ejercía una sexualidad no heteronormativa en la periferia de la imagen de lo costarricense.

Para 1986, la dinámica de la enfermedad presentó un crecimiento lento, pero una alta mortalidad. Según la Comisión Nacional de SIDA, quedó claro que el comportamiento de la sociedad influye en la manera en que se comportaba no solo el sida, sino también cualquier tipo de enfermedad venérea, lo cual llevó a asegurar que "la descomposición social de estas décadas ha favorecido el incremento de tales padecimientos. La promiscuidad sexual, el homosexualismo, la drogadicción, la prostitución, son, sin duda, las causas de propagación más importantes de estas enfermedades" (Solís, 1986a, 8). Este tipo de aseveraciones parecía no considerar que, la enfermedad se propagaba por un virus, no por una orientación sexual; el discurso médico con mayor autoridad sobre el tema en el país conceptualizó a la sexualidad no normativa como un síntoma, como un vehículo de propagación de enfermedades, una patología social.

¿Hubo algún tipo de acercamiento entre las autoridades de salud y las poblaciones con "alto riesgo" de contagio? La respuesta es afirmativa, el Instituto de Investigaciones en Salud (INISA) de la Universidad de Costa Rica al percatarse de que durante la primera mitad de 1986 los casos con un diagnóstico positivo al virus se duplicaron, empezó a estudiar con mayor profundidad a los grupos homosexuales. Al realizar estos análisis: 
Una de las mayores preocupaciones de los especialistas que se han encargado de analizar este tema en el territorio nacional es que el homosexualismo se hubiera incrementado. No hubo un estudio para afirmarlo, pero varios profesionales consideran que este grupo aumentó (Solís, 1986b, 6).

Aunque ese tipo de preocupaciones evidencia un contexto persecutorio, se torna necesario recordar que, durante la segunda mitad de los años ochenta, el discurso médico en su mayoría asociaba directamente a la enfermedad con el comportamiento sexual. Por esta razón, el "incremento" de la población homosexual resultaba preocupante, y al mismo tiempo reflejaba una inquietud sobre el posible aumento en los casos de infectados, pues hasta cierto punto, homosexuales y enfermos eran sinónimos.

Como parte de estos estudios del INISA, los médicos elaboraron una tipología de la homosexualidad y, en su afán de clasificación, lograron distinguir cinco tipos de homosexuales: gais, prostitutos, prisioneros, crípticos y cacheros (Mata, Ramírez y Rosero 21). Estas investigaciones del INISA se convirtieron en uno de los primeros trabajos científicos en abordar el tema de la homosexualidad en Costa Rica, bajo una importante herencia biologista. Dicha necesidad de clasificar y crear tipologías se enmarca en una tradición científica que busca ponerle orden a lo percibido como un fenómeno complejo.

Al respecto, el coordinador de la Comisión Nacional de SIDA, Leonardo Mata, en unas declaraciones a inicios de 1987 afirmó que, con respecto al sida:

Se ha visto que su incidencia se da más en naciones desarrolladas; es mayor en las áreas urbanas densamente pobladas, en sociedades con rasgos neuróticos, en grupos humanos donde falten mensajes que establezcan la diferenciación sexual, asi como en hogares donde hay debilidad del papel del hombre, y en general, donde exista desintegración familiar, problemas de drogas y exacerbadas cargas negativas provenientes de la liberación femenina (Mora 13).

La historia de la respuesta hacia el VIH/sida se había desarrollado en cuatro fases, comenzando con los peligros y las alertas en un contexto de emergencia, a uno donde se conceptualizó como un problema de comportamientos individuales, a una cuestión que tuvo relación con conductas socialmente contextualizados, para al final convertirse en un desafío vinculado con el discurso de los derechos humanos. La primera estrategia global sobre el tema articulada por la Organización Mundial de la Salud en 1987, definió al VIH/sida en términos de riesgos provenientes del comportamiento individual, definición directamente relacionada con una tradición de metodología epidemiológica que se aplicaba a factores individuales de riesgo predeterminados (Mann y Tarantola 5-6).

Como se puede observar en líneas anteriores, en el discurso médico nacional se utilizaban tanto factores de riesgo individuales como factores sociales. Las menciones del aspecto urbano y la densidad poblacional dan cuenta de esto. 
Además, se evidencia una fuerte carga de patologización mezclada con aspectos religiosos por parte del médico, en donde se enfatizaba en la diferenciación sexual familiar y la presencia de una figura masculina como necesarias para evitar una mayor incidencia de la enfermedad; así, de forma indirecta se dice que la homosexualidad es el resultado de una sociedad neurótica.

Por su parte, la crítica al movimiento de liberación femenina se podría analizar cómo un elemento más de esta visión en donde los papeles de género, la sexualidad normativa, el patriarcado y la conceptualización religiosa de la familia conformaban una suerte de barrera infranqueable que protegía a la sexualidad heteronormativa, y se erigía frente al contagio de la enfermedad.

En medio de este contexto frenético, se idearon medidas para impedir el aumento en el número de portadores e infectados, y a inicios de 1987 el viceministro de Salud, el Dr. Víctor Julio Brenes, propuso la posibilidad de crear un decreto para declarar obligatorio el examen del sida para los futuros estudiantes de las universidades, para quienes aspiraran a puestos públicos o privados y para parejas con deseos de contraer matrimonio (Diario Extra 4). Esta iniciativa produjo muchas polémicas, tanto en la población como en el mismo gremio de médicos, ante lo cual se llegó a establecer que dichos exámenes no se justificaban, y que era mejor circunscribirlos a los grupos de alto riesgo (La Nación 28). Para marzo de 1987, la dinámica de la enfermedad empezó a cambiar, y fue así como el grupo social con mayor cantidad de portadores pasó a ser el de los homosexuales (La Nación 9).

Al conocerse el informe de la Comisión de SIDA, en donde se establece que en el país podría haber 1500 portadores del virus, es el mismo Consejo Social del Poder Ejecutivo el que propuso la obligatoriedad del examen (La Nación 4); sin embargo, esta iniciativa nunca logró concretarse (La Nación 10). Eventualmente, se harían propuestas para declarar obligatorio el examen a todos los marineros que llegaran a las costas del país (La Nación 9), y voluntario para quienes se encontraran dentro la estructura presidiaria y en los centros de reclusión nacional (La Nación 10). Los exámenes obligatorios a todos los grupos considerados como una amenaza al cuerpo social son una evidencia de cómo el discurso médico tenía consecuencias reales y concretas en el accionar del Gobierno.

A lo largo de 1987, diversos médicos expusieron su opinión con respecto al contexto del VIH/sida; por ejemplo, el Dr. Juan Jaramillo Antillón afirmó que "si la población mundial en general tiende a ser normal en su relación sexual, no tiene por qué temer ser contagiada" (6). Por su parte, la Comisión Nacional de SIDA en un espacio pagado manifestó que "universalmente se acepta que la homosexualidad, la bisexualidad, la promiscuidad y la drogadicción, constituyen factores propiciadores de la propagación de este fatal padecimiento. Así mismo rechaza que los preservativos... hagan aceptable el uso anormal del sexo" (Ministerio de Salud 17). En un reportaje transmitido por Telenoticias, un médico explicaba 
“a los jóvenes que están desviados sexualmente, que deben cambiar sus hábitos y el que no pueda, que busque ayuda de especialistas -psiquiatras y psicólogos- dispuestos a colaborar" (Fonseca 5).

Para el coordinador de la Comisión de SIDA, al cuestionarse sobre lo que estaba mostrando el sida en términos de calidad de vida y estructura de la sociedad, lo anterior "expone un serio problema social, una grave descomposición social y un irrespeto craso a los principios de la moral y la ética" (Mata, 1987a, 15). Este mismo médico, al explicar algunas de las características del sida, afirmó que:

La respuesta a este peligro es el rescate de valores ahora erosionados, mayor recato y cuidado en todo lo que tiene que ver con el sexo, mayor énfasis en el sexo dentro de la unión estable, mayor educación sobre el sindrome y su prevención, y cuando sea preciso, el empleo de los preservativos (Mata, 1987b, 15).

El discurso médico se vio entremezclado con valoraciones personales acerca de la moral, la ética y la normalidad, y el lente de la patologización de las identidades sexuales fue desplegado ampliamente.

Las autoridades de salud afirman que pese al énfasis dado a la necesidad de que la población modifique su comportamiento sexual no da los resultados esperados, las campañas de educación del Ministerio y la Comisión de SIDA se enfocaron en comportamientos individuales, concentraron su atención en el aspecto moral de las acciones, al final de 1987 el número de enfermos por sida se había duplicado (La Prensa Libre 4)

Para inicios de 1988, el 60 por ciento de los portadores eran hombres homosexuales (La Nación 3), lo cual motivó a las autoridades de salud a emplear nuevas formas de acercarse a la población que practicaba o se identificaba con una sexualidad no heteronormativa, y educarla con respecto a la enfermedad; para esto, se imprimieron miles de folletos y se distribuyeron grandes cantidades de preservativos. En relación con este viraje en las campañas de prevención, el coordinador de la Comisión de SIDA afirmó: "no estamos promoviendo el uso del preservativo por sí mismo, pues consideramos que lo ideal es que las personas no hagan el acto sodómico" (La Prensa Libre 10). Se consideraba al preservativo como un mal necesario; a pesar de ser una medida de protección bastante eficaz para prevenir el contacto con fluidos de riesgo, la asociación del discurso médico con concepciones morales y religiosas seguía siendo una piedra en el camino para las campañas de educación.

En un artículo que ocupó la portada de La Prensa Libre en mayo de 1988, se establecía que: 
Una de las expectativas del Ministerio de Salud, por medio de diversas campañas, era que se redujera a uno el número de compañeros sexuales, además de que la relación sexual se llevara a cabo por la vía vaginal, que es la natural (2).

Si no se lograba que la población cambiara su forma de actuar sexualmente, no habría manera de detener la epidemia; a pesar de enfatizar en que no se estaba persiguiendo a ningún grupo en particular, existía el temor de que la enfermedad cruzara el puente y empezara a infectar personas heterosexuales (Semanario Universidad 13). La visión era apocalíptica, el discurso médico creaba una imagen donde la sexualidad tiene el potencial de traerse abajo a la sociedad.

Foucault (2008) ha analizado la forma en que la medicina ha estado obsesionada con el uso de los placeres sexuales desde el siglo XVIII, el autor establece que:

Aquel que carece de fecundidad y de compañero; el agotamiento progresivo del organismo, la muerte del individuo, la destrucción de su raza y finalmente el daño acarreado a la humanidad fueron prometidos, por lo general, a lo largo de una literatura prolifica, a quien abusase de su sexo. Estos temores inducidos parecen haber constituido, en el pensamiento médico del siglo $X I X$, el relevo "naturalista" y científico de una tradición cristiana que asignaba el placer al terreno de la muerte y el mal (21-22).

En respuesta a la campaña del Ministerio de Salud hubo voces críticas, el Dr. Henning Jensen, director del Instituto de Investigaciones Psicológicas de la Universidad de Costa Rica, manifestó que la campaña "ha fortalecido prejuicios sociales, hasta el punto que en la actualidad el sida y los homosexuales son conceptualizados como las secuelas de una época de liberalidad sexual, o sea, como un castigo" (Mora 21). Esta retórica médica oficial había traído como resultado una moralización del discurso, acentuando en la culpabilidad de ciertos grupos sociales. Por su parte, el epidemiólogo Dr. Mauricio Frajman establecía que "no hay un cambio en la actitud frente al sida por parte del Estado, se le sigue viendo como una enfermedad diferente. Pero no lo es, es una enfermedad viral de transmisión sexual, o sangre-sangre. Por eso se siguen manteniendo iguales conceptos y tabúes" (Semanario Universidad 8). A pesar de que se propuso un cambio en las campañas, estas seguían teniendo tintes discriminatorios, la sexualidad no heteronormativa como patología, como enfermedad y como desviación de la norma seguían siendo puntos centrales del discurso médico oficial.

El reconocimiento de la enfermedad por parte de los médicos rozó con dos ideas sociales centrales; una era la idea de la homosexualidad como una enfermedad o una patología, noción que se reforzó por las circunstancias, los discursos y las percepciones culturales. La otra giraba en torno al concepto de una epidemia. Así, el sida sacudió el mundo médico occidental, la enfermedad apareció como un recordatorio de períodos anteriores donde imperaron las infecciones fatales, el virus parecía sacado 
fuera de contexto, perteneciente a un distante pasado, anterior a los avances científicos y económicos que combinados habían logrado, hasta cierto punto, controlar a las plagas antiguas (Fee y Krieger 460-461).

Como ya se mencionó, el discurso médico en Costa Rica no fue homogéneo, sin embargo, en su gran mayoría, se conceptualizó a la sexualidad no normativa como una patología, y se le otorgó al comportamiento sexual individual un peso imposible de cargar, una culpabilidad que en lugar de provocar cambios positivos en la dinámica de la enfermedad, tuvo entre muchas de sus consecuencias la estigmatización de grupos sociales variados.

\section{¿Patología o pecado? Vínculos entre el discurso médico y el religioso}

El discurso médico no fue único en esa dinámica de patologización de la homosexualidad. La constante mención de una ruptura con el "orden natural" de los hechos, la utilización de palabras como pecado e inmoralidad daban cuenta de que el discurso religioso funcionaba como una nube de vapor que impregnaba las posiciones de muchas personas; junto al Estado estaba la Iglesia, y durante ese período, los sacerdotes, presbíteros e incluso el mismo Vaticano no se quedaron al margen de las discusiones sobre la enfermedad y su aparente relación con las sexualidades no normativas, por lo que es importante analizar su posición y la forma en que encuadraron los temas abordados. ${ }^{2}$ En una columna semanal llamada Comentario Religioso, el presbítero Juan Luis Mendoza (1985) abordaba diferentes temas desde una óptica pastoral, entre ellos la homosexualidad; en uno de esos artículos, el religioso afirmaba que:

Es claro que el homosexual no procede de acuerdo con la naturaleza... La conducta homosexual es reprochable, ciertamente ¿Quiere decir esto que nos hemos de andar escandalizando por ello? No. A las personas con este tipo de problemas hay que acogerlas con la debida comprensión y amor, más como a un tarado psíquico que como a un depravado moral. Despreciarlos es precipitarlos cruelmente al mundo de los marginados sociales y a la amargura de sentirse incapaces de superarse a sí mismos en el mal que los hace sufrir tanto (50).

La primera concordancia con el discurso médico; la naturaleza funciona como un argumento biológico que legitima el discurso, cubriéndolo con un manto científico. Además, se recurre a los elementos patologizantes para seguir entrelazando la posición religiosa con la prueba científica, se conceptualiza a la persona que practica o se identifica con una sexualidad no normativa como alguien sin las capacidades mentales para ser consciente de sus acciones; se le infantiliza, es un discurso paternalista.

La homosexualidad es caracterizada como un mal, una tendencia que hace sufrir a las personas, la daña. En esta afirmación está englobada cuanto vendría a ser la visión oficial de la Iglesia frente al tema; lo reprochable no era la persona homosexual, sino el acto, pues es considerado un pecado. No obstante, es posible que la persona 
logre redimirse de sus inclinaciones si decide no actuar sobre sus deseos, es decir, practicar la abstinencia. Este discurso adquiere fuerzas durante dicho período, y el eco que produce se dilata durante los años siguientes, y la visión dualista de tendencia homosexual/acto homosexual se convierte en uno de los pilares del dogma cristiano frente al tema.

Durante los años en que empiezan a encontrarse una mayor cantidad de portadores del virus, el discurso religioso comenzó a tomar más y más fuerza, amparado en el aparato estatal y en la visión de los principales ministros encargados de controlar la propagación de la enfermedad, la Iglesia se convirtió en un actor institucional bastante influyente.

El sida, al igual que en muchos otros lugares, empezó a ser caracterizado como "el producto del pecado, la inmoralidad y la ignorancia del ser humano" (Flores 16). Las consecuencias de la enfermedad eran tomadas como la prueba de una ruptura con la ley natural y el orden moral, se afirmaba que

Cuando el hombre, abusando de su libertad, corrompe este ordenamiento y proclama el amor libre, el homosexualismo, el desenfreno sexual, la infidelidad conyugal y el reino de los instintos las consecuencias no tardan en aparecer. Su alejamiento de Dios lo torna menos humano y esta deshumanización lo bestializa (Solano 18).

Aparece un elemento nuevo, además de ser un pecado, una patología y una ruptura, a la sexualidad no normativa se le considera también algo que deshumaniza a las personas, y el sida era el símbolo, la metáfora, el síntoma, el "mal de los vicios de nuestra civilización" (Cejudo 14).

El primero de octubre de 1986, el Vaticano publicó un documento titulado Carta a los obispos de la Iglesia Católica sobre la atención pastoral a las personas homosexuales, el cual constituye la primera manifestación formal de la máxima autoridad católica frente al tema de la homosexualidad. En relación con la Carta, el arzobispo Román Arrieta estableció que dicha ordenanza "aunque no pretende determinaciones en la esfera civil, sí desautoriza aquellas intenciones que persiguen defender la homosexualidad como el resultado de la práctica de un derecho humano" (Mora 13). El intento de desvincular a la sexualidad no normativa como parte de la estructura de los derechos humanos tiene resonancias con los discursos anteriormente expuestos en donde el acto homosexual niega la humanidad de las personas. Además, se pone de manifiesto que, aunque se intente esbozar un límite entre el accionar civil y el pensamiento religioso, ambos terminan influyéndose y reforzándose.

En relación con la Carta, el Eco Católico planteaba que esta "no solo es exquisitamente respetuosa con quienes sufren esa tendencia desordenada, sino también defensora de la libertad fundamental que está en la base de su particular dignidad como personas y, por tanto, también de la responsabilidad moral de sus actos" (6). 
Para el discurso religioso, el dividir el tema de la sexualidad entre tendencias y actos era una forma de establecer límites entre lo considerado como pecado y lo que tenía el potencial para serlo, la pastoral católica exhortaba a las personas homosexuales a suprimir su deseo, a redimirse a través de la castidad.

En el mismo contexto de la publicación de la carta del Vaticano, el pastor de la Iglesia Bautista, Jorge Gaitán manifestó que "el homosexualismo es una de las muchas manifestaciones visibles del pecado. Es una conducta que alimenta el egoísmo, y como tal no puede ser aceptada por su congregación” (Mora 13). La visión de la homosexualidad como parte de un estilo de vida en donde el hedonismo, el individualismo y el egoísmo eran sus principales características fue otro de los ejes discursivos de la óptica religiosa y médica durante este período.

Se empezó a colocar al matrimonio como la única alternativa frente a esta ruptura social. La creciente presencia de la sexualidad no normativa como tema constante en las discusiones públicas llevó a gestar un sentido de amenaza en donde la permisividad podía generar graves consecuencias. En un artículo de La Nación se establecía que "es tiempo de iniciar una cruzada para recuperar los valores abandonados tan irreflexivamente. ... No hay nada mágico ni terapéutico en las prescripciones de aquellos que se dicen 'liberados'. Sus vidas son superficiales, impersonales, solitarias y hedonistas" (46). El acto sexual dentro del matrimonio llegó incluso a ser considerado como "la mejor garantía para evitar posibilidades de contagio y transmisión del SIDA" (Runnebaum 15). Es interesante notar que desde el discurso religioso existía una imagen de la persona homosexual como carente de relaciones de apoyo, de comunidad, de familia; se le veía como un ser aislado, como un pecador solitario.

¿Hasta qué punto el discurso religioso, la publicación de la Carta del Vaticano y las diferentes conceptualizaciones de la homosexualidad por parte de la Iglesia católica y el gremio de médicos influyeron y tuvieron consecuencias materiales en las políticas estatales? Como ya se vio anteriormente, la posición de la Comisión Nacional de SIDA con respecto a la sexualidad no normativa era bastante clara: la homosexualidad cargaba bajo sus hombros el peso de la culpa por la propagación de la enfermedad, las acciones individuales eran consideradas como síntomas de esa patología social que cada día cobraba más víctimas; incluso, en las campañas de prevención, el preservativo siempre fue un último recurso, aunque las aseveraciones de la Comisión contra su uso fueron notables. En 1987, uno de los años más álgidos del pánico social por el sida, el Eco Católico publicó un artículo en el cual se plantea:

Como sucede en cualquier otro desorden moral, la actividad homosexual impide la propia realización y felicidad porque es contraria a la sabiduría creadora de Dios. La Iglesia, cuando rechaza las doctrinas erróneas en relación con la homosexualidad no limita sino que más bien defiende la libertad de la persona, entendidas de modo realístico y auténtico... El SIDA no es la totalidad del problema ni el tema central. Es un sintoma de algo más profundo y mortal. 
El SIDA no es sino una de las muchas consecuencias desastrosas de la promiscuidad sexual. Incluso a corto plazo el rearme moral es la mayor esperanza de la sociedad. La difusión de contraceptivos y jeringas para los drogadictos reducirá pero no suprimirá los peligros. Los sujetos a alto riesgo concluirán que un estilo de vida, potencialmente letal, puede ser seguro adoptando determinadas precauciones... No es, por lo tanto, la difusión del SIDA la razón por la que la Iglesia recuerda constantemente que se da en la actualidad un uso equivocado y enloquecido de la sexualidad. La Iglesia no dejará de repetirlo cuando se mitigue la difusión de tal enfermedad (Chacón 5).

El autor de dicho artículo fue el presbítero Leonel Chacón Mesén, quien además de sus funciones religiosas como director arquidiocesano de la pastoral de la salud y la tercera edad, también era uno de los miembros de la Comisión Nacional de SIDA. De esta forma, la proyección mediática que tenía la Comisión frente a temas como el uso del preservativo se relaciona directamente con el discurso religioso; tanto el Estado como la Iglesia se habían unido para no solo atacar a la enfermedad, sino también a todos aquellos grupos de riesgo que de una u otra forma representaran una amenaza para el orden natural, para la seguridad moral de la población.

El sida es tomado como un símbolo que le sirve al discurso médico y religioso para criticar los puntos de fuga, es decir, aquellos actos sexuales que no estén insertos en una dinámica conyugal, exclusiva, reproductora y heterosexual. El discurso médico y el discurso religioso tenían sus diferencias, pues no todos los médicos se basaban en la óptica religiosa; no obstante, la influencia que ambos discursos tuvieron sobre la conceptualización de la sexualidad no normativa, ya fuera como pecado, como patología o como ruptura, dio como resultado consecuencias materiales, la aparición del VIH/sida en Costa Rica acercó ambos discursos, acelerando un proceso de abyección social.

\section{Del pánico moral al gen gay, transición hacia la década de los noventa}

Los pronunciamientos en torno a qué tipo de sexualidad es la correcta no es en absoluto una cuestión del pasado, la segunda mitad de la década de los ochenta presenció el inicio de un debate sostenido nacionalmente sobre la homosexualidad, tema que interpela a diferentes sectores de la sociedad; médicos, psicólogos, religiosos, activistas y políticos forman parte de un engranaje que construye y reconstruye discursos y percepciones frente a una realidad que, en la Costa Rica de las últimas tres décadas, ha ido adquiriendo una creciente visibilización. En la coyuntura de la aparición del $\mathrm{VIH} /$ sida, los procesos de abyección y estigmatización a los que fueron expuestas la identidad y la práctica de las sexualidades no normativas se vieron reforzados por la falta de oportunidades para escuchar voces disidentes y por la ausencia de espacios que permitieran crear resistencia; no obstante, el incipiente activismo y la organización politizada lograron atenuar la avalancha de discursos que se abalanzaba sobre diferentes grupos de personas (Jiménez 77-83). 
Una vez que llegó la década de los noventa (re) surgen conceptos que dinamizaron la discusión; diversidad sexual, orgullo, derechos humanos y minorías sexuales. La sexualidad que se encontraba al margen social, en la periferia erótica, empezó a moverse hacia el centro, comienza a encontrar su propia voz, deja de aceptar el desfile de discursos de manera estoica, propone, critica y demanda, entabla una serie de nuevos objetivos y agendas políticas, construye una ciudadanía sexual.

$\mathrm{Al}$ mismo tiempo, los actores sociales e institucionales que de una $\mathrm{u}$ otra forma se opusieron a la creciente toma de espacios culturales de la sexualidad no normativa comenzaron a reorganizarse; ante la estructuración de una agenda de diversidad sexual, los grupos políticos conservadores y la religión católica toma nuevas posiciones, refuerzan sus discursos y establecen alianzas.

La transición que evidencia la sexualidad no normativa durante este contexto evidencia que, cuando el VIH/sida dejó de ser un eje monotemático, se empezaron a gestar nuevas problemáticas, las políticas de identidad vienen a complejizar el paisaje de demandas sociales de la Costa Rica en los albores del nuevo milenio. ¿De qué maneras el discurso sobre la sexualidad no normativa cambió en comparación con la década de los ochenta?

Como ya se vio con anterioridad, la Comisión Nacional de SIDA publicó en 1987 espacios pagados en donde afirmaba no solo que la homosexualidad era una de las causas de la enfermedad, sino que también exhortaba a las personas a evitar el "uso anormal del sexo" (Ministerio de Salud 17). Cinco años después, en 1992, la misma Comisión publicó ciertas declaraciones, una de ellas titulada Derechos fundamentales de la persona portadora del VIH y el SIDA, en la cual se proclama que toda persona que tenga el virus es jurídica y socialmente igual al resto de la población y también se condenó toda forma de estigmatización. En uno de los puntos se estableció "el derecho a ser respetado(a) en el desempeño de sus actividades sociales, laborales, de relaciones afectivas y en el ámbito de su sexualidad, esta última de acuerdo con las respectivas recomendaciones de protección científicamente conocidas" (Comisión Nacional de SIDA 12). Este viraje en el discurso, en donde se pasó de condenar algunas prácticas, a un llamado para respetar el derecho de auto determinación sexual evidenció que, en cuestión de unos pocos años, ciertos discursos médicos oficiales dejaron de lado la estigmatización como herramienta de persuasión.

Durante la década de los noventa, la dinámica en el discurso médico mostró que existía una imperiosa necesidad por "descifrar" las verdades de la homosexualidad, mediante diferentes aproximaciones, se buscó establecer datos fuertes, con tintes científicos que permitieran dilucidar la realidad fija de las sexualidades no normativas. La genética, la psiquiatría y la psicología buscaban abrir las cerraduras del secreto de toda aquella sexualidad que no calzara con la norma. La diversidad sexual era un fenómeno al cual había que acercarse a través de la óptica científica; se creía que en los genes y en la mente de las personas se encontraban los misterios sexuales a la espera de ser develados. 
Esta dinámica en donde la homosexualidad se convirtió en un objeto de investigación empieza a gestarse en Costa Rica durante toda la primera mitad de la década del noventa; por ejemplo, la cuestión de la tipología es un tema que interpeló a muchos individuos, uno de ellos era el psicólogo Danilo Echeverría, el cual afirmaba que "dentro de esta población se deben distinguir tres tipos. Primeramente, el que se dedica a vender su cuerpo, el cual posee problemas mentales debido principalmente a que desde niño se le educó como niña y no como varón," para luego manifestar que "otra de las razones puede ser el posible abuso sexual que haya tenido desde pequeño, lo que viene a repercutir en su adolescencia. El otro tipo de homosexual es aquel que oculta su gusto por los hombres al resto de las personas... El último grupo es el de los bisexuales" (Tabash 15). Esta obsesión por clasificar a las personas, imponiéndoles características inamovibles y fijas, es en sí mismo un acto disciplinario, ante el aparente caos y ansiedad social que trae la visibilización de nuevas formas de vivir la sexualidad, se volvió necesario para ciertos grupos el restablecer el orden, y una de las formas para lograrlo es clasificando, haciendo tipologías, creando conocimiento que permita darles sentido a dinámicas sociales anteriormente invisibilizadas.

El mismo psicólogo puntualizó que "los muchachos deben de educarse desde su niñez y orientarlos hacia patrones de conducta correctos, porque pueden generar desviaciones mentales que repercutirían en el desarrollo del joven y consecuentemente en su forma de actuar" (Tabash 15). Por su parte, para el subdirector de la Escuela de Medicina de la Universidad de Costa Rica, Dr. José Eliseo Valverde (1992):

Es muy importante que los niños tengan buenos consejos de sus padres y maestros de escuela, con el propósito de que jamás tropiecen con malos hábitos de relacionarse sexualmente, evitando así el homosexualismo y el bisexualismo, es especial esto último, por tratarse de una degeneración en todo aspecto (13).

La homosexualidad se asomó como una amenaza para la juventud, como un patrón erróneo de comportamiento, una desviación de la norma. A los ojos de este discurso médico, establecer e imponer las formas "correctas" de vivir la sexualidad, lejos de ser algo discriminatorio, se vio como un llamado de la moralidad. La abyección como proceso de caracterización de identidades siguió presente, y la asociación de las sexualidades no normativas con otro tipo de elementos negativos fue una estrategia ampliamente utilizada por los discursos médicos.

En un artículo para La República, el genetista Francisco Cruz afirmó que "está el caso del niño que desde que nace tiene tendencias hacia lo femenino: quiere vestirse como mujer, tener el pelo largo, es muy fino, delgadito. Eso viene genéticamente determinado" (Martí y López 10). Por su parte, en el mismo artículo, para la psicóloga Carmen Aybar "no se puede negar el factor socioambiental, pues el elemento social y las experiencias previas en el desarrollo sexual de una persona -como abusos sexuales u otros- pueden influir en la escogencia" (10) para luego manifestar que 
"se ha determinado que la configuración del cerebro de un heterosexual es distinta a la de un homosexual” (Martí y López 10). Según la psicóloga Mirna Calderón de la Comisión Nacional de SIDA, "existen muchos hombres con serios problemas de indefinición de su sexualidad... los homosexuales sobrevaloran la masculinidad, hay mayor narcisismo, ellos admiran la belleza masculina, visten ropa cara y fina" (Fernández 9).

Esta frenética búsqueda por la verdad de la sexualidad lleva a buscar diferencias fisiológicas entre diferentes grupos sociales, a utilizar la genética como una herramienta que sedimenta de manera definitiva los comportamientos de las personas, caracterizándolas como las simples marionetas de genes autoritarios que crean un cierto sentido de certidumbre; es más sencillo explicar dinámicas sociales complejas reduciéndolas a aspectos genéticos fuera de nuestro control (Papili 12).

La búsqueda de un gen gay (Segura 8), se inserta dentro de una dinámica más amplia en donde impera una cierta certeza de que las variaciones en los deseos sexuales solo pueden ser legítimas si se comprueba que son inmutables, naturales e innatas. La razón por la cual algunas ramas del discurso médico y ciertas organizaciones en pro de la diversidad sexual buscaban comprobar desesperadamente la existencia de un factor biológico determinante para la orientación sexual es porque existe la noción de que el deseo estará justificado si se muestra que no hay otra alternativa; este tipo de óptica frente a las variaciones eróticas se basaba en un supuesto bastante problemático, según el cual solo los deseos genéticamente determinados son legítimos. Sin embargo, hoy estos se asumen como naturales y normativos, como el amor romántico igualitario heterosexual, no fueron parte de la historia de la humanidad hasta hace poco, y dependieron de políticas culturales y procesos sociales e históricos (Katz, 2012).

\section{Conclusiones}

Si bien en la segunda mitad de la década de los ochenta, el discurso había sido reaccionario basado en tabúes culturales para describir el sida, hubo un cambio internacional que permitió comenzar a interpretar la realidad con otra perspectiva. A inicios de la década, en mayo de 1990, la Organización Mundial de la Salud (OMS) retiró la homosexualidad de su corpus internacional de clasificación de enfermedades y problemas de la salud, en una apuesta por la despatologización (Warner 9-12).

Sin embargo, la influencia que tuvo esa acción médica/política en los discursos y percepciones médicas de Costa Rica durante el periodo analizado fue poca. En el ámbito nacional siguió imperando una visión de la homosexualidad como una patología, como un problema social que requería de intervención médica para develar sus secretos y corregir sus desviaciones. No obstante, el pronunciamiento de la OMS no pasó totalmente desapercibido, pues en 1993 el Dr. Martín Varela (1993) afirmó que "la homosexualidad no puede, en plan riguroso, conceptuarse como una entidad, un síntoma o una enfermedad" (13). 
El pronunciamiento de la OMS no tuvo un impacto directo en el contexto nacional, pero el eco de sus repercusiones funcionaría como un impulso más que tuvo el activismo por la diversidad sexual para desafiar el discurso patologizante, y buscar formas de visibilizar su propia existencia. Este proceso de medicalización de la sexualidad, en general, y de la homosexualidad, en particular, se caracteriza por su carácter "científico" (Jordan 144-149); es decir, se presenta a sí mismo como una "verdad revelada". Es a través de la medicalización que se implantaba en el cuerpo toda una matriz de significados de orden biomédico (Vendrell 97). Este proceso de biopoder busca regular la vida a partir de prácticas y discursos que vinculan el saber especializado o científico y el poder institucionalizado, con el objetivo de vigilar, administrar y controlar la sexualidad y los cuerpos.

El lenguaje crea realidades, y la realidad que creó el discurso empleado por los médicos y los religiosos durante el contexto de aparición del VIH/sida en Costa Rica fue de una comunidad de hombres homosexuales que, de manera general, conformaba una enfermedad en sí misma. Las imágenes utilizadas para concebir esta comunidad son bastante abyectas: hombres promiscuos, irresponsables, practican sexo antinatural y cargan sobre sus espaldas la responsabilidad por el surgimiento de plagas y enfermedades.

Los discursos médicos, influenciados en gran parte por la óptica religiosa, emplean una serie de caracterizaciones para referirse al contexto social y, específicamente, a la creciente visibilización de la sexualidad no normativa, por ejemplo el de la culpabilidad, la descomposición social, la desintegración familiar, el pecado, el tarado psíquico, la deshumanización, ser una bestia, una tendencia desordenada, un estilo de vida hedonista y egoísta, una patología social, una enfermedad, una amenaza a la salud de la Nación, un grupo anormal, un colectivo de desviados, la representación del más absoluto irrespeto a la moral y la ética y un pecado. Entre los lugares geográficos en donde se imagina a esta comunidad imperan los lugares públicos y urbanos densamente poblados, incluso uno de los discursos llega a conceptualizar dichos espacios como característicos de sociedades con rasgos neuróticos.

La principal paradoja, o contradicción, que se puede analizar en esta dinámica recae en el hecho de que, el discurso médico, en su afán de controlar la vida sexual de la población, terminó por establecer una serie de medidas de prevención que tuvieron un efecto limitado en su objetivo de mejorar la condición de salud de las personas; aunque la meta principal era bajar los índices de contagio, el discurso médico y, en parte, el religioso, promovieron la creación de una comunidad que a los ojos de la población, en general, era la responsable de las enfermedades, lo cual incidía en la poca efectividad de las campañas de prevención. Así, la sexualidad no heteronormativa se convirtió en el principal blanco de estos discursos, teniendo como otra de sus consecuencias paradójicas, una visibilización sin precedentes en el país del tema de la sexualidad no normativa. 


\section{Notas}

El tema de los discursos médicos vinculados con la salud en Costa Rica se ha visto enriquecido por una variedad de investigaciones que han buscado problematizar y analizar las diferentes maneras mediante las cuales el gremio médico ha conceptualizado y representado a la enfermedad y el mundo social que la rodea. Uno de esos trabajos es el de Malavassi (2003) en donde se analiza el discurso médico y científico frente a la lepra. Por su parte, Palmer (2003) rastrea la institucionalización de la disciplina médica en Costa Rica, al darle atención a los discursos sobre medicina popular y la manera en que para 1920 la promoción estatal había colocado al médico como el máximo garante del conocimiento científico. En una dinámica similar, Marín (2006) analiza los cambios en la percepción de la prostitución, entre estos el médico y científico, así como la forma en que fue reglamentada durante parte de los siglos XIX y XX. Gamboa (2009) examina los discursos al interior del Hospital Nacional Psiquiátrico, a través de entrevistas y análisis de expedientes médicos, y logra determinar la posición del discurso con respecto a temas como la homosexualidad, la moral y las categorías psiquiátricas. Fernández (2016) se aproxima al discurso sexológico a través de un análisis de programas televisivos que abordan temas de sexualidad, con lo cual se evidencia el carácter mórbido y profiláctico de ciertas posiciones científicas. Finalmente, Soto (2014) analiza el discurso médico frente al tema de lo trans, y discute sobre el papel de la patologización de dichos discursos en la conformación de subjetividades. En conclusión, este tema podría desarrollarse mucho más, principalmente desde las ciencias sociales se pueden plantear múltiples temáticas que problematicen y pongan en disputa la conformación de los discursos médicos en general, y los vinculados con la sexualidad en específico, a lo largo del tiempo y en diferentes contextos.

El desarrollo que ha tenido el protestantismo en la región latinoamericana durante gran parte de la segunda mitad del siglo XX evidencia una creciente fuerza y relevancia, llegando incluso a presentar desafíos para la Iglesia católica, se afirma que "el movimiento evangélico en América Latina ha experimentado un considerable crecimiento numérico, aumentando al mismo tiempo su presencia simbólica en la sociedad, sus demandas políticas y culturales" (Fediakoya 10). Para el caso costarricense, la expansión del protestantismo evangélico se evidencia en el número de devotos, los cuales se han triplicado entre 1978 y 1986 (de 50 mil a más de 150 mil creyentes). En 1990 cerca de un 10 por ciento de la población costarricense iba a servicios evangélicos ocasionalmente, proporción que se estabilizó en un 16 por ciento para el 2002. El discurso evangélico es conservador y ha sido propagado por misiones estadounidenses. Este éxito de los evangélicos revela que la Iglesia católica se ha quedado atrás del cambio social y cultural, la población nominalmente católica bajó de 90 a un 76 por ciento entre 1985 y el 2002 (Molina y Palmer 169-170).

\section{Bibliografía}

Bogantes, N. "Preguntan sobre SIDA". La Nación [San José], 23 de agosto de 1985: 14.

Butler, Judith. Violencia de Estado, guerra, resistencia. Por una nueva politica de la izquierda. Trad. Patricia Soley-Beltrn. Madrid: Editorial Safekat, 2011.

Butler, Judith. El género en disputa. El feminismo y la subversión de la identidad. Trad. María Antonia Muñoz. Barcelona: Paidós, 2007.

Butler, Judith. Lenguaje poder e identidad. Trad. Javier Sáez y Betatriz Preciado. Madrid: Editorial Síntesis, 2004.

Butler, Judith. “Actos performativos y constitución de género: un ensayo sobre fenomenología y teoría feminista". Debate Feminista, 18 (1998): 296-314. 
Cejudo Velázquez, Pablo. “El SIDA y natura”. La Nación [San José], 9 de mayo de 1986: 14.

Chacón Mesén, Leonel. "Preocupación de la Iglesia por la enfermedad del SIDA". Eco Católico [San José], 2 de agosto de 1987: 5.

Chaves, José Ricardo. Paisaje con tumbas pintadas en rosa. Heredia: Editorial de la Universidad Nacional, 2000.

Comisión Nacional de SIDA. "Derechos fundamentales de la persona portadora del VIH y SIDA". Diario Extra [San José], 23 de marzo de 1992: 12.

“Obligatorios exámenes preventivos". Diario Extra [San José], 5 enero de 1987: 4.

"Atención pastoral a homosexuales". Eco Católico [San José], 2 agosto de 1987: 6.

Fee, Elizabeth y Nancy Krieger. "The Emerging Histories of AIDS: Three Successive Paradigms". History and Philosophy of the Life Sciences, 15(3) (1993): 459-487.

Fediakova, Evguenia. "Protestantismo misionero norteamericano en América Latina en el siglo XX". Persona y Sociedad, 21 (1) (2007): 9-37.

Fernández, Milena. “Un asunto de doble moral”. La República [San José], 22 de marzo de 1992: 9.

Fernández Fernández, Daniel. "La sexología frente al cuerpo de las biomujeres: un análisis crítico a partir de dos programas televisivos". Cuadernos Intercambio, 13 (1) (2016): 69-92.

Flores, Mario H. “SIDA y espiritualidad". La Nación [San José], 1 septiembre de 1985: 16.

Fonseca de Sibaja, Lidiette. "Sobre el SIDA". La Nación [San José], 13 de mayo de 1987: 5.

Foucault, Michel. El orden del discurso. Trad. Alberto González Troyano. Venezuela: Tusquets Editores, 2005.

Foucault, Michel. Historia de la sexualidad 2- el uso de los placeres. Trad. Martí Soler. Buenos Aires: Siglo XXI Editores, 2008.

Gamboa Barboza, Isabel. En el Hospital Psiquiátrico. El sexo como locura. San José: Editorial Universidad de Costa Rica, 2009.

Grmek, Mirko. Historia del SIDA. Buenos Aires: Siglo XXI, 2004.

Gómez Meza, Juan Olivier. Luchas maricas y derechos humanos en América Latina. Heredia: Editorial Amo Al Sur, 2012.

Jaramillo Antillón, Juan. Salud y seguridad social. San José: Editorial UCR, 1993.

Jaramillo Antillón, Juan. "Nueva era en las relaciones sexuales de costarricenses". La República [San José], 30 de marzo de 1987: 6.

Jiménez Bolaños, José Daniel. "La criminalización de la diversidad sexual y el inicio del activismo gay en Costa Rica, 1985-1989". Revista Rupturas, 6 (1) (2016): 61-90.

Jordan Young, Rebecca. Brainstorm. The Flaws in the Science of Sex Differences. Massachusetts: Harvard University Press, 2011.

Katz, Jonathan. La invención de la heterosexualidad. México: Editorial Me Cayó el Veinte, 2012.

"Aclaran que riesgo de contraer SIDA es alto en ciertos grupos". La Nación [San José] 29 de agosto de 1985: 2.

“Medidas de prevención.” La Nación, [San José], 2 de septiembre de 1985: 12.

"El INISIA realiza estudios sobre anticuerpos de SIDA". La Nación [San José], 4 septiembre de 1985: 1.

"Preocupa falta de reactivos para detectar SIDA en el país". La Nación [San José], 10 septiembre de 1985: 2.

“Darán cursos sobre SIDA en reunión de microbiólogos". La Nación [San José], 5 de diciembre de 1985: 9.

“El matrimonio, única alternativa". La Nación [San José], 14 de marzo de 1987: 46.

“Tres casos más de SIDA". La Nación [San José], 17 de marzo de 1987: 9. 
"Proponen examen del SIDA a funcionarios públicos". La Nación [San José], 24 de marzo de 1987: 4.

"Prueba de SIDA provoca polémica". La Nación [San José], 27 de marzo de 1987: 28.

"Limitarán prueba de SIDA". La Nación [San José], 7 de abril de 1987: 10.

"Control estricto sólo para marineros, difundirán en exterior medida contra SIDA". La Nación [San José], 1 de septiembre de 1987: 9.

“Recluso con SIDA". La Nación [San José], 27 de octubre de 1987: 10.

“Primeros dos casos de SIDA en 1988". La Nación [San José], 8 de enero de 1988: 3.

"Personas rehúsan modificar costumbres sexuales". La Prensa Libre [San José], 5 de diciembre de 1987: 4 .

"Homosexuales forman asociación anti-SIDA". La Prensa Libre [San José], 3 de marzo de 1988: 10.

"25\% de los hombres son bisexuales en Costa Rica". La Prensa Libre [San José], 28 de mayo de 1988: 2.

Labra, Oscar. "Social Representation of HIV/AIDS in mass media: Some important lessons for caregivers". International Social Work 58 (2) (2015): 238-248.

Malavassi Aguilar, Ana Paulina. Entre la marginalidad social y los orígenes de la salud pública. Leprosos, curanderos y facultativos en el Valle Central de Costa Rica (1784-1845). San José: Editorial de la Universidad de Costa Rica, 2003.

Mann, Jonathan y Daniel Tarantola. "Responding to HIV/AIDS: A Historical Perspective". Health and Human Rights 2 (4) (1998): 5-8.

Marín Hernández, Juan José. La tierra del pecado, entre la quimera y el anhelo: Historia de la prostitución en Costa Rica, 1750-2005. San José: Alma Mater, 2006.

Martí, Ángela y Gustavo López. “Aceptados u odiados, son parte de la sociedad y ahora, organizados, defienden sus derechos". La República [San José], 2 de noviembre de 1999: 10.

Mata Jiménez, Leonardo. “EL SIDA y los niños". La Nación [San José], 16 de julio de 1987a: 15.

Mata Jiménez, Leonardo. "El SIDA y la mujer". La Nación [San José], 9 diciembre de 1987b: 15.

Mata, Leonardo, Giselle Ramírez y Luis Rosero. “Tipología y conducta de riesgo de infección con el virus de la inmunodeficiencia adquirida (HIV), de hombres homosexuales en Costa Rica, 1985- 1987". Revista Ciencias Médicas 9 (3) (1988): 21-35.

Mendoza, Juan Luis. “Los homosexuales”. La Nación [San José], 24 de febrero 1985: 50.

Ministerio de Salud. "Pronunciamiento de la Comisión Nacional del SIDA". La Nación [San José], 12 de abril de 1987: 17.

Ministerio de Salud. Plan Estratégico Nacional (PEN) en VIH y Sida 2016. San José: Dirección de Planificación Estratégica y Evaluación de las Acciones en Salud, 2016.

Mohs, Edgar. “El SIDA y los niños.” La Nación [San José], 3 de septiembre de 1985: 15.

Monge Zeledón, Rose Mary. “Dudas y mitos que deben aclararse.” La Nación [San José], 2 de septiembre de 1985: 12.

Molina, Iván y Steven Palmer. The History of Costa Rica: Brief, Up-to-date and Illustrated. San José: Editorial UCR, 2012.

Mora, William. "Iglesia encara homosexualismo". La Nación [San José], 25 de enero de 1987: 13.

Mora, William. "SIDA atemoriza a ticos". La Nación [San José], 10 de enero de 1988: 21.

Palmer, Steven. From popular medicine to medical populism: Doctors, healers, and public power in Costa Rica, 1800-1940. Durham: Duke University Press, 2003.

Papili, Marilú. “Es la homosexualidad un problema genético?”. La Prensa Libre [San José], 5 de marzo de 1994: 12. 
Pecheny, Mario. "Introducción: Investigar Sobre Sujeto Sexuales". Todo sexo es político: estudios sobre sexualidades en Argentina Eds. Mario Pecheny, Carlos Figari y Daniel Jones. Buenos Aires: Libros del Zorzal, 2008.

Robinson, Shirleene y Emily Wilson. "Working Together? Medical Professionals, Gay Community Organizations and the Response to HIV/AIDS en Australia, 1983-1985". Social History of Medicine 25 (3) (2012): 701-718.

Runnebaum, Carlos E. “Forma correcta de evitar el SIDA". La Nación [San José], 22 de marzo 1988: 15.

Segura, William. "Genética loca: descubren genes de homosexualidad, suicidio y anti temor". Al Día [San José], 22 de mayo 1996: 8.

"Recomendamos el examen, aunque no es obligatorio: Entrevista a Edgar Mohs". Semanario Universidad [San José], 14 de abril de 1989: 13.

"La educación sobre SIDA es inadecuada: Entrevista a Mauricio Frajman". Semanario Universidad [San José], 14 de abril de 1989: 8.

Solano Cerdas, Claudio. "SIDA y moral”. La Nación [San José], 2 de septiembre de 1985: 18.

Solís, María Isabel. "Se redujeron los males venéreos". La Nación [San José], 6 de junio de 1986a: 8.

Solís, María Isabel. "Aumentan personas con anticuerpos del SIDA". La Nación [San José], 25 de agosto de 1986b: 6.

Soto Rodríguez, Mario Andrés. “La patologización de la transexualidad: contemplando posibilidades de resistir desde algunas construcciones de género no hegemónicas". Cuadernos Intercambio 11 (2) (2014): 145-165.

Tabash, Ahmed. “No tiene nombre”. La Prensa Libre [San José], 3 de junio de 1992: 15.

Valverde Monge, José Eliseo. “Grupo de alto riesgo". La Nación [San José], 3 octubre de 1992: 13.

Varela, Martin. "La homosexualidad". La Prensa Libre [San José], 20 de marzo de 1993: 13.

Vendrell Ferré, Joan. "El impacto de la medicalización del sexo en relación con la construcción de la identidad de género y sexual". Diversidad sexual: justicia, educación y salud. Memorias de la VI Semana Cultural de la Diversidad Sexual. Eds. Edith Peña Sánchez y Lilia Hernández Albarrán. México: Instituto Nacional de Antropología e Historia, 2010.

Vendrell Ferré, Joan. Pasiones ocultas: De cómo nos convertimos en sujetos sexuales. Barcelona: Editorial Ariel, 1999.

Warner, Michael. The Trouble with Normal: Sex, Politics and the Ethics of Queer Life. Massachusetts: Harvard University Press, 1999.

Weeks, Jeffrey. Sexuality. Londres: Routledge, 2003. 
José Daniel Jiménez Bolaños. Costarricense, obtuvo su licenciatura en Historia por la Universidad de Costa Rica, es egresado de la maestría académica en Historia de la misma universidad. Se desempeña como profesor de la Escuela de Historia y la Escuela de Estudios Generales de la Universidad de Costa Rica. Es autor de los artículos “De lo privado a lo público: La celebración del Orgullo LGBTI en Costa Rica, 2003-2016" (2017), "La criminalización de la diversidad sexual y el inicio del activismo gay en Costa Rica, 1985-1989" (2016), “Temáticas en construcción: El desarrollo de los estudios LGBT en Costa Rica, 1980-2013" (2014). También ha laborado como historiador en el Teatro Nacional de Costa Rica.

Contacto: josedaniel.jimenez@ucr.ac.cr

ORCID: orcid.org/0000-0002-8868-7729

Mario Bahena Uriostegui. Mexicano, es un profesor asociado en la Johnson C. Smith University en la ciudad de Charlotte, Carolina del Norte. Desde 2010, se desempeña como director del Programa de Español en dicha universidad. Obtuvo su licenciatura y maestría en Filosofía y Letras en la Loyola University en la ciudad de Chicago, Illinois. En 2010, obtuvo su doctorado en literatura mexicana en la Indiana University Bloomington, en el estado de Indiana. Su investigación se enfoca en las ansiedades y ambivalencias en los cada vez más medios de comunicación social donde las identidades construidas discursivamente circulan, tratando de controlar nuestro imaginario social.

Contacto: mbahena@jcsu.edu

ORCID: orcid.org/0000-0003-3418-3741 
